\title{
¿La memoria de los paisajes o los paisajes de la memoria? Los enigmas de la sustentabilidad socioambiental en las geografías en disputa
}

\section{Memória das paisagens ou paisagens da memória? Os enigmas da sustentabilidade socioambiental nas geografias em disputa}

\section{The Memory of the Landscapes or the Landscapes of the Memory? Puzzles of the Socio-Environmental Sustainability in Disputed Geographies}

\author{
Juan Carlos SKEWES* \\ Debbie GUERRA** \\ Pablo ROJAS ${ }^{* * *}$ \\ María Amalia MELLADO****
}

\begin{abstract}
RESUMEN
La inteligibilidad de la relación de una población con su territorio depende del enfoque que se use para comprenderla. La evaluación social de los impactos ambientales representa una perspectiva profundamente occidental cuya aplicación tiene efectos devastadores para las comunidades locales siendo la consecuencia principal el desalojo de la memoria que está anclada en el paisaje. La separación de la memoria del paisaje constituye el fin de la sustentabilidad socioambiental para un grupo humano, en cuyo caso la memoria migra desde el mundo de las cosas hacia la memoria de las cosas. La encarnación paisajística de una comunidad es desenraizada y condenada a seguir existiendo solamente en el recuerdo que las personas tienen de su territorio. Es estudio de impacto ambiental para la construcción de un proyecto hidroeléctrico en las inmediaciones del Lago Neltume en el sur de Chile muestra que la mirada externa erra al identificar adecuadamente los contornos de la ocupación humana del territorio. El
\end{abstract}

\footnotetext{
"Ph.D., Antropólogo, professor do Instituto de Ciencias Sociales da Universidad Austral de Chile, Email: jskewes@uach.cl

** Antropóloga, professora do Instituto de Salud Sexual y Reproductiva, Investigadora, Centro de Estudios Ambientales (CEAM). Universidad Austral de Chile. Email: dguerra@uach.cl

*** Estudante de Antropologia, Universidad Austral de Chile. Email: pablorojas212@hotmail.com

**** Estudante de Antropologia, Universidad Austral de Chile. Email: melladomariaamalia@gmail.com
} 
estudio del caso invita a formular un análisis paisajístico para evidenciar la existencia de una simbiosis socioambiental que encapsula la memoria de la comunidad en el paraje local, garantizando en el largo plazo la continuidad del poblamiento y, con ello, la sustentabilidad. La discusión permite sugerir formas alternativas de evaluar impactos ambientales, haciéndose cargo de los patrones que gobiernan los modos de emplazamiento de las poblaciones humanas.

Palabras clave: sustentabilidad socioambiental; paisaje; conflictos ambientales; estudios de impacto ambiental.

\title{
RESUMO
}

A inteligibilidade da relação de povo com seu território depende do enfoque que se use para compreendê-la. A avaliação social dos impactos ambientais representa uma perspectiva profundamente occidental, cuja aplicação tem efeitos devastadores para as comunidades locais, sendo a consequência principal o desalojamento da memória que está ancorada na paisagem. A separação da memória da paisagem constitui o fim da sustentabilidade socioambiental para um grupo humano, em cujo caso a memória migra desde o mundo das coisas em direção à memória das coisas. A encarnação paisagística da uma comunidade é desenraizada e condenada a seguir existindo somente na lembrança que as pessoas têm de seu território. O estudo de avaliação de impactos ambientais para a construção do projeto da usina hidrelétrica nas imediações do Lago Neltume, no sul do Chile, mostra que o olhar externo erra em identificar adequadamente os contornos da ocupação humana do território. O estudo do caso convida a formular uma análise paisagística para mostrar a existência da simbiose socioambiental que encapsula a memória da comunidade na paragem local, garantir-se no longo prazo a continuidade do povoamento e, com ele, a sustentabilidade. A discussão permite sugerir formas alternativas de avaliar impactos ambientais, cuidando dos padrões que regem os modos de localização das populações humanas.

Palavras-chave: sustentabilidade socioambientais; paisagem; avaliação de impactos ambientais.

\begin{abstract}
The intelligibility of the relation between population and territory depends on the approach that is employed for understanding it. The social evaluation of environmental impacts represents a deeply western perspective that in its application has devastating effects over the local communities. The main effect is the memory's dislocation of the environment in which it is embedded. The dissociation of the memory from the landscape signals the end of a group's socio-environmental sustainability, in which case the memory migrates from the environment to the remembrance of the environment. The landscaped embodiment of the community is uprooted and the community is forced to live upon the memory of the territory that once they had. The environmental impact assessment for a hydroelectric project in Neltume lake, in southern Chile, shows that the approach fails in identifying the nature of the human occupation of the territory. The case study invites to deploy a landscape analysis that demonstrates de socio-environmental symbiosis that embodies the community history in the local environment, focusing on the patterns that rule the modes of occupation of the human populations.
\end{abstract}

Key-words: socio-environmental sustainability; landscape; environmental impact assessment.

\section{Introducción}

En el lago Neltume se conserva un patrón de asentamiento de la población local de origen mapuche que humaniza el paisaje en la misma medida que el paisaje se torna humano. La memoria e identidad local están contenidas en las formas que adopta el asentamiento, formas cuya comprensión deviene de las claves culturales que sus habitantes manejan. La memoria, desde esta perspectiva, se asienta simultáneamente en el recuerdo de las habitantes, en sus prácticas sociales y rituales y, sobre todo, en el 
paisaje del que son parte. Es la memoria de los paisajes que da continuidad a un poblamiento que ha permitido la sustentabilidad socioambiental en un área de refugio que hoy se ve amenazada por la intervención de una empresa hidroeléctrica que procura cambiar el curso de las aguas para la generación de energía. La intervención externa amenaza con trocar la memoria de los paisajes en los paisajes de la memoria, reestructurando la localidad por la vía de la intervención externa.

La lectura del caso permite reflexionar, por una parte, acerca de las bases sociales de la sustentabilidad y, por la otra, contrastar las prácticas locales con las lecturas que del territorio se hacen a partir de los estudios de impacto ambiental (EIA). En la mirada de los estudios de impacto ambiental se encarna la racionalidad dominante $y$, como resultado, una parte importante de la escena local se invisibiliza, facilitando el desmantelamiento de las modalidades de arraigo prevalentes en las comunidades locales. El contraste pone en evidencia la necesidad de establecer nuevas formas de pensar el paisaje a fin de salvaguardar el patrimonio local socioambiental frente a la intervención externa.

El caso que permite ilustrar el desencuentro de dos racionalidades en la construcción de la Central Hidroeléctrica Neltume por parte de la empresa ENDESA Chile, filial de ENERSIS, que afecta a la comunidad mapuche Juan Quintuman del lago Neltume, en la Región de Los Rios, en el sur de Chile. El proyecto, por medio de la desviación de las aguas del rio Fui hacia el lago, busca generar energía eléctrica para ser entregada al Sistema Interconectado Central. Se trata de una central de pasada de $490 \mathrm{MW}$, con una generación anual media de $1.870 \mathrm{GWh}$, la cual contará con dos turbinas, y que requiere, previo a su construcción, estudios litológicos y estructurales del material donde se proyecta el emplazamiento de la caverna de máquinas (ENDESA CHILE 2009). Aprovechando la topografía del lugar, la construcción de la central verterá aguas que sumergirán el lugar sagrado donde se realiza la principal rogativa (nguillatún) de la comunidad, además de comprometer una parte importante de la vida local.

\section{Paisaje, memoria y sustentabilidad}

El paisaje, entendido como el conjunto de interacciones entre personas e hitos, entre el topos y sus habitantes, es la síntesis simbiótica entre seres humanos y naturaleza. El paisaje, a diferencia de la sociedad o del ambiente, entraña la asociación evanescente de significados e hitos, e importa la lugarización del mundo A partir de una comprensión histórico-política del paisaje es posible dar cuenta de las modificaciones, creaciones y percepciones de la naturaleza implicadas por la cultura y agencia humanas, incluyendo las dimensiones materiales e inmateriales, y las dimensiones discursivas y emocionales que intervienen en su modelado (SELLIN, 1996; STOKOWSKI, 2002). El paisaje es el resultado de la interacción entre el entorno, las poblaciones que los habitan y los significados que se le asocian (NAVEH, 2000). Esta perspectiva considera las prácticas sociales, ideas, modos de simbolizar y cogniciones que interactúan en los procesos históricos a través de los que se configuran los paisajes (CRUMLEY, 1994; DESCOLA, 1996; PATTERSON, 1994). Constituye el paisaje, desde este punto de vista, el lugar de la memoria. En otros términos, el paisaje es un contenedor de la memoria (STEPHENS, 2002).

El paisaje es un ejercicio de lugarización a través del que se confiere sentido al espacio: el espacio no es lugar si no entraña un significado (RICHARDSON, 1999). Los lugares existen tanto en lo ideacional como en lo material de modo que la memoria colectiva es un importante ingrediente en la formación de lugar y en las identidades que se le asocian: en el lugar se sedimenta la memoria (STEPHENS, 2002). La memoria se nutre, en este sentido, de los lugares que le contextualizan. El paisaje, en tanto condensación de lugares, puede ser tenido como un almacén de la memoria colectiva, un locus de los recuerdos, un almacén que aglutina diversas capas materiales experienciales cuya superposición le confiere identidad. La identidad del paisaje se deriva, pues, de las múltiples memorias y significados asociados a un determinada locación y que confieren un sentimiento de pertenencia y apego a sus habitantes (SILVERMAN, 2002; STEPHENS, 2002).

El paisaje se construye material y discursivamente, condicionándose recíprocamente ambas dimensiones. Cada lugar o región "llega" al momento presente trayendo consigo largas historias. Los paisajes son, en este sentido, dinámicos y cambian del mismo modo como se transforman las poblaciones que les habitan, las que crean múltiples $\mathrm{y}$, en ocasiones, yuxtapuestos, paisajes, basadas en múltiples factores tanto geográficos, ecológicos, culturales, económicos, sociales, políticos, como ideológicos, - tanto de carácter situacional como de largo alcance (SILVERMAN, 2002). Estos paisajes, además, pueden ser co-optados por generaciones ulteriores o por grupos coetáneos- Los paisajes son, así, "cultivados". 
La noción de práctica o agencia es crucial para comprender la variedad de intervenciones que las colectividades humanas despliegan en su interacción con la naturaleza. El paisaje es relacional y se produce a través de la práctica de sujetos históricos. El proceso especial y la identidad del paisaje es siempre materia de poder y de contestación más que de una cierta autenticidad (MASSEY, 2007). Más aún, la práctica social es siempre espacial en tanto ocupa y crea espacio, pero al mismo tiempo esta espacialidad construye y constriñe la acción. La dinámica y recursividad de la vida espacial se beneficia de una aproximación analítica basada en la práctica, la agencia y la estructuración (SILVERMAN, 2002). Sherry Ortner (1984) confiere a la noción de práctica un carácter eminentemente político. Cualquier acción a través de la que un actor individual o colectivo, ciñéndose a planes de corto o largo plazo, procura producir cambios en su entorno. Sus intenciones, circunscritas por una estructura de oportunidades y restricciones, le llevan a generar coaliciones con otros actores y eventualmente a transformar o reproducir las estructuras en las que operan (GIDDENS, 1984; MELUCCI, 1991).

Los paisajes resultan de la acción intencionada, imaginativa y creativa de poblaciones humanas frente al ambiente, y su existencia no puede entenderse sino como fruto de la relación dialéctica entre poblaciones y los medios que históricamente han adquiridos para encarar su reproducción. La obra seminal de Karl Polanyi (1944) fue visionaria al introducir la oposición entre una economía encarnada (embedded) y otra descarnada (disembedded), surgida a partir del desarrollo del capitalismo a escalas crecientes, la que progresivamente fue determinando lo local por procesos extra-locales, marcados por la apropiación de recursos naturales y fuerza de trabajo para satisfacer el interés externo (HARVEY, 2004). James O'Connor (1998) define la segunda contradicción del capitalismo como el desmantelamiento que el afán de lucro provoca en las condiciones de producción (la naturaleza, la fuerza de trabajo y la infraestructura comunitaria. La producción capitalista no produce tales condiciones sino más bien las transa en tanto bienes ficticios. La expansión del capital determina la aceleración en el uso de estos recursos, provocando un incremento en los precios y poniendo en jaque la propia producción capitalista.

Los planteamientos de O'Connor se mantienen aún en un paradigma que no reconoce a la naturaleza su lógica propia, concibiéndola desde una perspectiva económica como un objeto determinado por relaciones sociales (BE-
DOYA; MARTÍNEZ, 2000). La invitación es a considerar al ser humano como parte de la naturaleza y no fuera de ella. Enrique Leff (2003) subraya la necesidad de generar conceptos que puedan hacerse cargo de esta relación. $\mathrm{Su}$ propuesta convoca a una nueva visión del proceso civilizatorio de la humanidad fundada en la racionalidad ambiental, donde se conjugan las autonomías locales, la democracia y la productividad de la naturaleza.

La prospección de modalidades alternativas de vinculación sociedad-naturaleza pasa por la investigación de los impactos que la expansión capitalista ha tenido en economías no capitalistas y en el estudio etnográfico de ensamblaje naturaleza - sociedad. En este ejercicio se corre el riesgo de generar una visión romántica de sociedades no occidentales en una relación armónica con la naturaleza, este ideal es más bien un discursos occidental que se atribuye a las comunidades locales, indígenas y no indígenas. No hay nada en otras sociedades que sugiera que haya existido una relación armónica o estable con la naturaleza (WEERATUNGE et al, 2000, p. 249). A través de su estudio acerca de las transformaciones en el Amazonas brasileño, Schmink y Wood (1987) contribuyen a esclarecer las avenidas que la investigación de los impactos del capitalismo a nivel local debe transitar. En su estudio, los autores demuestran que la presión ejercida sobre las comunidades locales lleva desde la reproducción simple a una economía de producción ampliada y, con ello, a una mayor degradación del entorno. El estado, en un contexto de frontera, por su indefinición $\mathrm{y}$ favoritismo hacia grupos empresariales, deja abiertas las puertas para una explotación ilimitada de los recursos. La situación descrita por estos autores invita a considerar la doble complejidad de los procesos locales: su vinculación con el entorno regional e internacional y su complejidad interna, en términos de los intereses dispares que se despliegan en la población.

La inclusión de las relaciones de poder en el análisis de los paisajes locales resulta fundamental para entender la articulación de los procesos locales con el entorno regional. La ecología política se ha interesado en el tema del poder y la inequidad no sólo en función de estudios locales sino en la interacción con las dinámicas del colonialismo y de las presiones ejercidas por la economía capitalista (PAULSON et al., 2003, p. 208; HARVEY, 2007).

Un segundo aspecto a considerar es la naturaleza de los fragmentos que se constituyen a partir del impacto que la expansión del mercado trae aparejado consigo. En este plano, las identidades sociales y culturales influyen en la 
relación entre los grupos humanos, las dinámicas medio ambientales y la expansión de los mercados. Factores sociales como el género, la identidad étnica, la clase, o la inclinación política, condicionan el conocimiento, decisiones y acciones de las personas en relación al medio ambiente (PAULSON et al., 2003, p. 209).

La lógica de la reproducción simple estaba anclada en un marco de relaciones locales y extralocales dominado por relaciones de intercambio al tanto que la instauración de una lógica de producción ampliada supone el desmantelamiento de tales redes, permitiendo la existencia de una multilocalidad o mundos separados articulados a la mono explotación de los recursos naturales. La indagación etnográfica permite caracterizar la fragmentación resultante al tiempo que reconoce las simientes de formas inesperadas de entrelazamiento de los diversos fragmentos involucrados en los nuevos paisajes.

La noción de paisaje se asocia a una la idea de una naturaleza comprensiva e interpretativa, que busca incluir la relación de los humanos y no-humanos en el desarrollo del territorio. Con ello además añadimos elementos simbólicos en la relación con la naturaleza: conocimientos locales, cosmovisiones, desde un punto de vista no-utilitario, sino como una naturaleza que es pensada y habitada por distintos actores sociales.

El acceso, control y uso del paisaje se define en un contexto histórico a partir de la interacción con actores sociales globales, los agentes del Estado y los mercados. Es para estos dos últimos que el manejo de la complejidad de la naturaleza y los diversos actores sociales encontrados en un paisaje se torna un desafío que es necesario simplificar a través de distintas herramientas generadas a partir de una ciencia cartesiana y reduccionista, que transforma al paisaje - y humanos - en números y cuadriculas (SCOTT, 1998), dejando consciente o inconscientemente de lado las complejidades de las relaciones sociales del paisaje. Esta mirada se condensa, en el contexto del desarrollo económico actual, de los estudios de impacto ambiental (EIA).

Los EIA se inscriben en una concepción que atribuyen al medio ambiente el carácter de una realidad autónoma y externa a las relaciones sociales y, como tal, de objeto pasivo de un conocimiento ilustrado, científico y, por tanto, generador de una conciencia única, base de un consenso universal, mirada que se constituye en la doxa ambiental (ZHOURI, 2008, p. 98). Los EIA, desde esta perspectiva, corresponden al proceso de identificar, predecir, evaluar y mitigar los efectos biofísicos, sociales y otros relevantes asociados a propuestas de desarrollo antes de adoptar las decisiones y compromisos principales (IAIA, 1999). La "crisis ambiental" se presenta como una realidad objetiva que puede ser encarada por medio del conocimiento técnico moderno y sujeta, por tanto, a diagnósticos y soluciones mitigadoras y compensatorias (ZHOURI, 2008, p. 101). El juego político, por tanto, se da en un contexto de adecuación ambiental orientado a viabilizar un proyecto técnico, incorporando algunas "externalidades" ambientales y sociales y medidas mitigatorias y compensatorias, sin, en caso alguno, poner en riesgo la iniciativa.

Los términos de referencia de los EIA no pasan de ser formulismos que pueden replicarse sin mayores modificaciones de una obra a otra, de carácter informativo y que eluden referencias ecológicas, culturales y sociales locales. Se trata de documentos que son contratados por la empresa con el fin específico de lograr la aprobación de los proyectos, que no incorporan las demandas específicas de la comunidad, y que se presentan como registros objetivos e incuestionables de la realidad (LEMOS, 1999, citado por ZHOURI, 2008). Los EIA se caracterizan, según Zhouri (2008, p. 102), por una visión patrimonialista, catastral y mercantil, que se hace cargo de las propiedades afectadas en tanto objetos pasivos de indemnización y no de los sujetos afectados, con sus intricadas formas de apropiación y uso del territorio, además de su vínculos societarios y culturales.

De esta forma se asegura la dominación del espacio por una visión hegemónica que asegura las posibilidades de uso de los recursos naturales para el beneficio del mercado. En este proceso se anulan las diversidades culturales en función de una visión fragmentaria, validada por la ciencia y el derecho e impuesta con el propósito de representación del bien común (ZHOURI, 2008, p. 100). Para esta autora, siguiendo a Wolfang Sachs, se impone una revolución de la eficiencia (del mercado) por sobre una revolución de la suficiencia (de las personas) y con ello no se garantiza una sustentabilidad en un sentido general que abarque a la sociedad en su conjunto.

Lo que se pretende a continuación es analizar el perfil que de la comunidad local hace un EIA a objeto de poner en evidencia omisiones cuya presencia tiene efectos devastadoras para las comunidades locales. El ensamblaje local entre seres humanos y no humanos se diferencia de la pobre construcción occidental que separa cultura de naturaleza, sujeto de objeto, y materia de idea. El EIA es, en este sentido, la antesala de un desalojo de proporciones: el de la memoria que está anclada en el paisaje, lo que constituye el 
fin de la sustentabilidad socioambiental de un grupo humano. La mirada técnica yerra en su intento por delinear los contornos de la ocupación humana del territorio. El estudio del caso revela la existencia de una realidad desmesurada en relación a lo que de ellas se quiso demostrar. El ilustrar esta realidad tiene el doble propósito de dar cuenta de un patrón de ocupación de una gran profundidad histórica y de abrir paso a una reflexión acerca de cómo transformar los EIA de modo que efectivamente se pongan al servicio de una sustentabilidad sustantiva. Para ello se plantea un análisis paisajístico que da cuenta de la simbiosis socioambiental que instala la memoria de la comunidad en el paraje local, garantizando en el largo plazo su sustentabilidad. Esta memoria del paisaje, una vez desmantelada por la acción del capital, pasa a ser el recuerdo que las y los moradores conservan como un signo identitario, desposeído de materialidad pero abierto a nuevas modalidades de expresión.

\section{Las fuerzas de la historia}

El medio donde se levanta la Central Hidroeléctrica de Neltume corresponde a un área de refugio a que han accedido las comunidades mapuche de la región de los Ríos en el sur de Chile. Hasta fines del siglo diecinueve los territorios ocupados por las comunidades indígenas en esta área permanecieron relativamente independientes del control chileno. La llamada Pacificación de la Araucanía (1861-1892) sometió a dominio chileno las tierras costeras y centrales de lo que hoy es la región de La Araucanía, al norte del área de estudio. Producto del sometimiento territorial de los mapuche, en 1883, comienza un proceso de radicación que llega tardíamente a Panguipulli (VERGARA et al., 1996). La historia regional está marcada por una colonización tardía. En el área de "Panguipulli, la situación era distinta, pues los territorios mapuches aún mantenían cierta

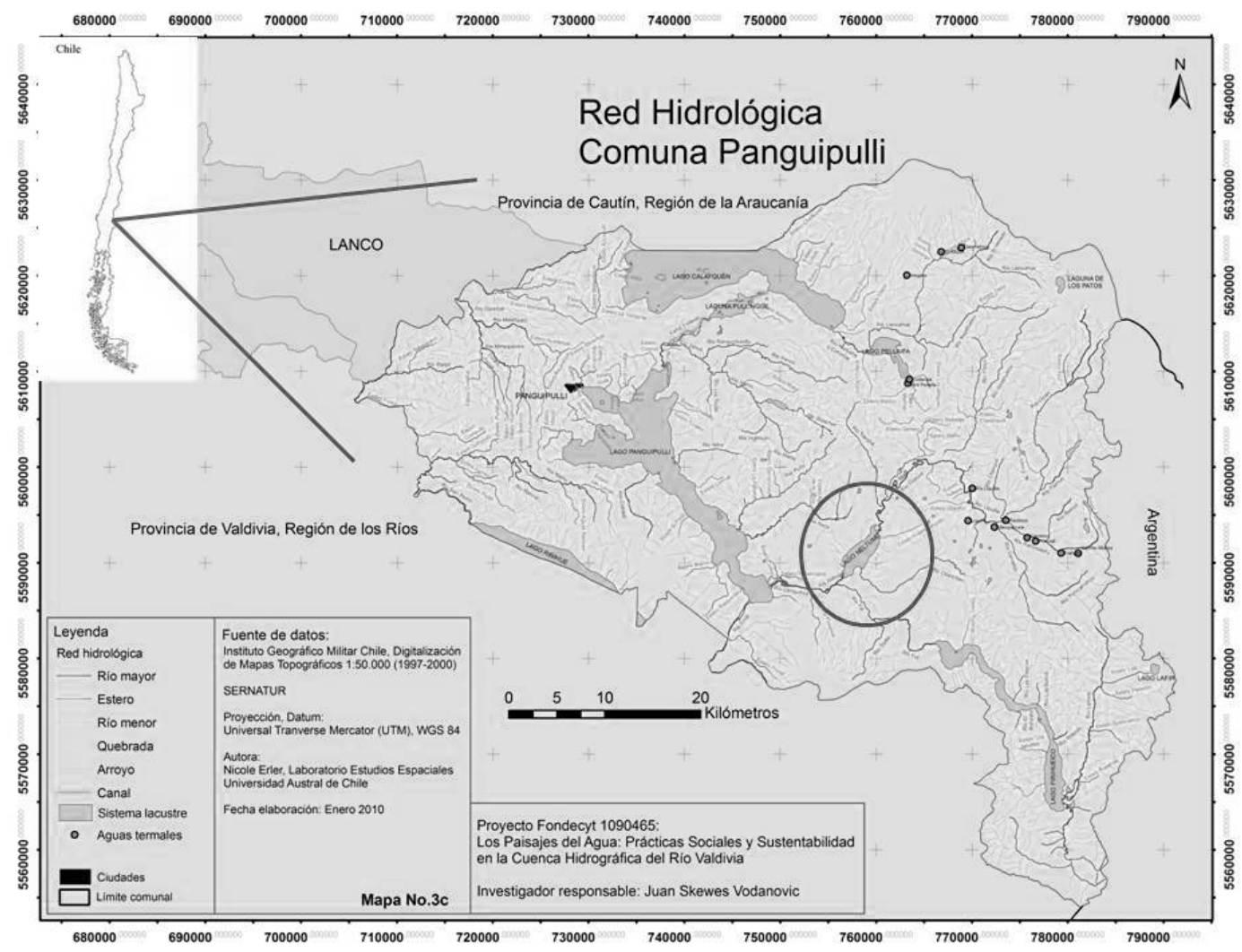

MAPA 1 - UBICACIÓN DEL LAGO NELTUME EN LA COMUNA DE PANGUIPULLI 
integridad, debido a la baja penetración hacendal y haber mantenido la autonomía" (COMISIÓN, 2008, p. 849). La presencia chilena aquí parte con una misión capuchina en 1904 pero el pueblo mismo se funda en 1938 (ALARCÓN, 1958). Su existencia es el fruto de una creciente industria maderera que desplazó a las poblaciones indígenas hacia los márgenes de su ocupación (RIVAS, 2006).

El lago Neltume aparece como la base de un estrecho corredor verde entre los montes y se desprende del eje de penetración chilena que va desde Lanco, en la depresión intermedia, hacia Argentina, en un contexto de profundas transformaciones históricas derivadas de la penetración chilena. Esta se materializa, primero, en el control de las tierras forestales de mayor plusvalía, y luego con la fundación de los principales centros poblados (Panguipulli, Neltume, Choshuenco) que, entre los años cincuenta y sesenta vieron su época de mayor esplendor derivado de la industria de la madera (ALARCÓN, 1958; JALABERT, 2010). Asimismo, durante parte importante del siglo veinte, el área se dinamizó a través de la habilitación y construcción de vías de acceso (lacustres y viales, primero, y ferroviarias después) (RIQUELME, 1968).

La comunidad indígena residente encuentra refugio en la ribera norte del lago. El nombre Neltume significa "ir a la libertad" o "andar libre" (RIVAS, 2006, p. 32; ALARCÓN, 1958). Siguiendo patrones tradicionales de ocupación del suelo, la comunidad se asienta en las laderas de los cerros cuya accidentada topografía los tornan inviables para la penetración chilena. La legalización del asentamiento comienza con la definición de fiscales de las tierras cordilleranas, "regularizando" la autoridad central las residencias la propiedad indígena. Así se crea la comunidad Juan Quintumán, a la que se confiere un Título de Merced en el año 1913, correspondiente a 743 hectáreas.

La población local se vio fuertemente influida por el desarrollo forestal maderero de la zona. Tanto la venta de mano de obra como el arriendo de yuntas de bueyes para el traslado de la leña y una cierta abundancia de dinero permitieron a la comunidad sortear una buena parte del siglo veinte. La situación cambió drásticamente con la llegada al poder del régimen militar en 1973. En el período anterior, el gobierno de Salvador Allende había creado el Complejo Forestal y Maderero de Panguipulli sobre la base de la expropiación y anexión de 22 fundos - uno sólo de los cuales contaba con sus escrituras al día - que cubrían una superficie de 3600 has. Durante su máximo apogeo el complejo llegó a ocupar a 3000 trabajadores (MEMO-
RIAL, 2010; RIVAS, 2006). Este escenario es recordado por las comunidades como un período de abundancia. El golpe militar termina con este proyecto, desmantelándose la organización y entregando las tierras a manos privadas. El sistema de plantaciones de especies exóticas se impone, excluyendo a la comunidad indígena del acceso a recursos básicos que le habían sido fundamentales para su existencia. El temor, el hambre y la supervivencia se imponen como forma de vida en los años que siguen.

La penetración maderera trajo consigo cambios poblacionales a partir de los años treinta del siglo pasado. Los obreros no tardaron en formar familia con las mujeres mapuche del sector. No obstante, la organización de los grupos familiares se reformuló sobre la base de la matriz mapuche. "Nosotros sabimos donde nacimos", dice doña María P., "mi abuelo mío nació en Pelauco. Soy de Temuco, los hombres van a buscar trabajo, lo mismo las mujeres, buscan compañía en otro lado. Así llegamos nosotros como familia que somos P. Buscamos trabajo, hacemos la casa y buscamos mujer. [...] Ahí vinieron a enredarse con tres o cuatro familias, buscando trabajo se encontraron con las mapuchitas y les dieron comida y ahí quedaron enredados". El arraigo es el fruto de la cultura, de la tierra, del alimento y del matrimonio. Ciento treinta y seis familias habitan el territorio que hoy entra en nueva disputa.

\section{Bajo mirada ajena}

Paradójicamente, lo que fuera la gran defensa natural de la comunidad se torna en su principal riesgo en el tiempo presente. La inclinada topografía no resultaba atractiva para empresarios extractivos que veían madera allí donde había bosque y costos donde no había caminos ni rutas de penetración. La mirada cambia cuando lo que se valora es la energía que se puede producir merced del uso de esas pendientes para desplazar las aguas en un proyecto hidroeléctrico. El problema radica en la ubicación del proyecto que coincide con el emplazamiento de la comunidad Juan Quintuman. La tarea consiste, desde el punto de vista de ENDESA, en producir un EIA que facilite la operación y que compense a mínimo costo a la comunidad por el impacto de las obras.

El EIA da cuenta de la mirada de la empresa hacia el medio comunitario: "Es una población con predominio adulto masculino, económicamente activa, con un comportamiento demográfico que tiende a expulsar población joven, básicamente mujeres, en busca de mejores 
condiciones de vida" (INGENDESA, 2010, Anexo W, p. 14). La "expulsión" de la población ha permitido según el mismo estudio "descomprimir presión sobre la propiedad de la tierra". La lectura del EIA evidencia en el lenguaje sus propias debilidades. La palabra expulsión, en este caso, invisibiliza un rico patrón migratorio que caracteriza a la población mapuche y que le permite plásticamente hacer frente a los desafíos del presente: quienes salen a trabajar no desertan su tierra sino que complementan las posibilidades de sobrevivir en ella. Sin embargo, la mirada externa advierte un subproducto del comportamiento sociófugo que previamente ha definido. "Esta distribución y comportamiento demográfico", sigue el EIA, "ha generado dos grupos que son estructuralmente vulnerables: niños y adultos mayores. Los niños [...] constituyen un grupo de demanda orientado a la calidad de su escolarización básica [...] Los adultos mayores [...] [son] especialmente vulnerable[s] si se relaciona su calidad pasiva con las actuales condiciones de salud, ingreso y vivienda". No está claro en esta lectura si los adultos mayores y niños o niñas se encontrarían en mejores condiciones en las perfirerias urbanas. El patrón pareciera ser otro: procurar la mejor protección bajo las condiciones actuales de niñas y niños y ancianos.

La economía local, en la perspectiva del EIA, no puede ser otra que la de pobreza: la población vive de las pensiones estatales de las y los ancianos "que constituyen la principal fuente de ingreso junto a la precaria producción predial de autoconsumo. Este grupo requiere apoyos especialmente en sus condiciones de habitabilidad y salud" (INGENDESA, 2010, Anexo W, p. 14; énfasis nuestro).

El diagnóstico hecho por el EIA enfatiza el pobre desempeño escolar de los menores, sin hacer mención a la calidad de la oferta educacional que se ofrece, y la dependencia de la comunidad hacia los sistemas médicos oficial (con sólo un tercio de la población local recurriendo a la medicina indígena provista por especialistas de otras comunidades). "El ingreso per cápita es cercano a los sesenta dólares mensuales y se obtiene en un $78,7 \%$ de actividades extraprediales. Se puede concluir una situación mayoritaria de pobreza", señala el informe (INGENDESA, 2010, Anexo W, p. 20).

Los bienes patrimoniales de la comunidad son listados de acuerdo a criterios convencionales en los ámbitos de la las consultorías arqueológicas: Árbol ceremonial; Cementerio indígena; Cancha de nguillatún o nguillatúe y palenque; 5 sitios arqueológicos; tres descansos, una iglesia católica, una iglesia metodista pentecostal y una iglesia evangélica. La mirada analítica permite así desglosar personas, actividades y bienes y ofrecer, sobre esa base, un perfil para hacer los cálculos que permitan estimar el impacto de la intervención, sin atender a la forma como están relacionados los hitos descritos.

Una pregunta legítima a formular al EIA es: ¿cuál es la comunidad a la que se refiere? El texto del EIA se restringe a la mirada externa de carácter analítico, catastral, fuertemente centrado en la dimensión material y con un énfasis marcado en la pobreza y en las malas condiciones de vida de la comunidad local. Este diagnóstico da cuenta de una comunidad campesina, indígena, más bien típica de las zonas cordilleranas de suelos empobrecidos y con evidentes dificultades de conectividad.

En la aplicación de este pensamiento analítico se contribuye a crear las condiciones para desenraizar a las comunidades locales y para desmontar la cosmovisión y práctica que la vincula orgánicamente con la naturaleza: "Dios nos tiene bien", reclama uno de los antiguos de la comunidad, "porque nosotros somos gente, como los chilenos. Por eso no puede llegar Endesa a sacarnos, ¿dónde quiere sacarnos Endesa? A los arenales por ahí [...] No queremos estar llorando allá afuera". Su voz deja entrever el "fuera" que marcaría el desarraigo de una comunidad que se sabe parte del lago: "Si nos vamos, vamos a llorar con pena y nos vamos a morir".

\section{La memoria del paisaje}

El enraizamiento paisajístico es lo que verdaderamente está en disputa al momento de generar una imagen acerca de los procesos locales. El conflicto en torno al proyecto involucra dimensiones cosmológicas y sociales que encuentran su raíz en la vinculación que la comunidad tiene con el volcán, con las aguas y con los árboles (ALDUNATE, 1997) y en los modos como ha sido infiltrada por la expansión capitalista (TOLEDO, 2007). Estas dimensiones se replantean frente al conflicto que supone la apropiación del agua para los fines de generación de energía eléctrica.

Lo que los ojos del experto ocultan es la intricada conexión de la comunidad y su paisaje, la simbiosis que entre humanos y no humanos se ha llegado a constituir a orillas del lago Neltume. El análisis de esta ceguera nos permite descubrir no sólo el error sino que avanzar hacia la comprensión de modalidades de acoplamiento socioambiental que nos son desconocidas y, con ello, poner de 
manifiesto la oportunidad de concebir el territorio de una manera diversa a la prevalente.

La posibilidad de hacer este ejercicio, con la ayuda de los actores locales, parte por reposicionar la mirada, por situarla en la perspectiva local y descubrir qué es lo que esta mirada ofrece como perspectiva. El testimonio y la práctica de vida, tanto en sus aspectos materiales como inmateriales, establece un sistema de coordenadas inescapables: una que une los volcanes Villarrica, Mocho y Choshuenco y la otra que sigue el curso de las aguas hasta el lago Neltume. Son estos y no otros los ejes que marcan la existencia social de las y los habitantes pretéritos y actuales del lago (ADAN et al., 2007; ALDUNATE, 1997; MUNITA et al., 2010).

El presente debe ser leído a partir de la tensión originaria que se dio entre, por una parte, los volcanes, y, por la otra, las fuerzas de las aguas, movilizadas por la serpiente kaikai y la protección sagrada del treng-treng, cerro donde encuentran refugio los antiguos (ver también FOERSTER, 1995).

La situación actual es tenida como una amenaza a la condición originaria, la que está marcada por la tensión permanente entre los volcanes Villarrica y Choshuenco. Las furias volcánicas del Villarrica, según las voces locales, son apaciguadas por las respuestas del Choshuenco: en el pasado el volcán Mocho se vio descabezado por uno de los truenos lanzados por el Villarrica.

Los "volcanes son resuellos de la tierra que nos dejó mi Dios", dice la vecina antigua de la parte más alejada de la comunidad. "Como nosotros mismos, ¿cuánto no resollamos? Tenemos los huequitos para resollar. La tierra está viva, no está muerta. Pero donde vaya, la tierra, cuando nieva, si usted cava está calentito, no está helada". Las voces del volcán, de las tierras, de las aguas y de los vientos ordenan a los humanos a revisar su conducta, siendo el guillatwé (como se denomina en Neltume al guillatún) o la rogativa sagrada el medio para hacerlo. Cuando la tierra tiembla hay que preparar el guillatwé, "hay que sacrificar un animal a Chao Dios, porque él da todo da todo, la vida, la fuerza, da todo".

"Por eso nos dejó nuestro padre esta tierra, a los mapuche, quien no sabe donde vaiga, qué generación, Abel con Cain, recibió con el cordero. Siempre mapuche, vaiga donde vaiga, necesita dejar el cordero El más bonito de todos tenemos que dejar, mismo que sea rico tiene que ha- cer, y esa sangre se deja en el agua. Nosotros los mapuches comemos de la tierra", dice don R. J. "Porque nosotros que somos nacidos y criados aquí, nosotros mapuches, salimos así de la tierra", asegura don R. J. "Las nuevas generaciones y los chilenos que viven en el pueblo, como en Neltume, yo creo que no hacen nada. Pero el verdadero, que sabe dar cuenta, se porta, ahí donde vaiga se porta. Nosotros los mapuche no se deja pasar nguillatún ${ }^{1}[$...] Por eso parimos donde nacimos".

La importancia del nguillatún, que es transversal a las comunidades mapuche, en el caso particular del lago Neltume, pone en evidencia el anclaje de la comunidad a su medio. Una junta de autoridades tradicionales se convoca en la ladera del treng-treng, el cerro sagrado, bajo el árbol ceremonial (roble pellín, nothofagus obliqua). La historia local de esta fase de la ceremonia es especialmente

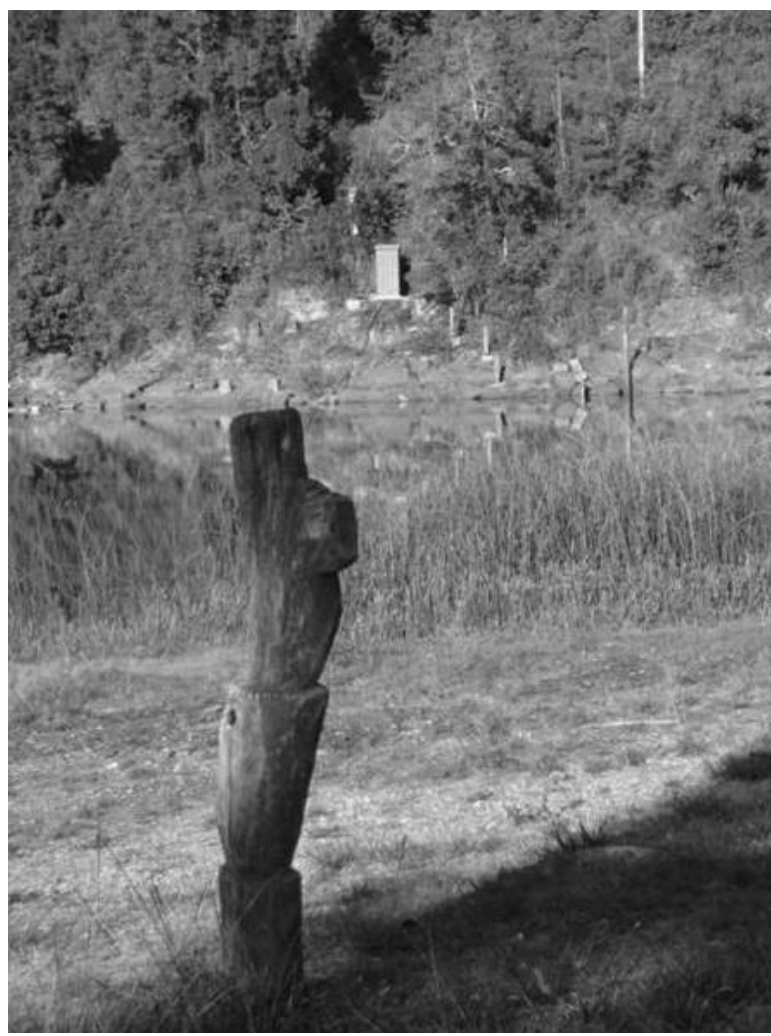

FOTO 1 - CAMPO DE NGUILLATÚN. ${ }^{1}$ Las y los residentes hablan de nguillatue más que de nguillatún. Ello es interesante pues el énfasis se coloca en el hue, esto es en el lugar ceremonial. Sin embargo,
dado que toda la literatura hace referencia a nguillatún, se ha preferido conservar esta expresión, evitando con ello confusiones. 
elocuente pues, a la inversa de cómo lo sugiere la literatura (FOERSTER, 1995), el actual treng-treng, donde se realiza la junta subió literalmente para el terremoto de 1960. El treng-treng, en este caso, eligió el lugar donde se hace la junta para levantarse.

El motivo central de la ceremonia, celebrada en los comienzos del verano cada dos, tres o más años, lo constituye el sacrificio ritual de un toro que se ofrenda a las aguas del lago a fin de asegurar la prosperidad de la tierra y el buen curso de los acontecimientos. En la mirada local las aguas conectan el mundo, especialmente al volcán con su lago. "Donde vaya hay agua caliente, hay minerales", describe una de las mujeres. "Hay agua caliente, en esta tierra, por debajo, a donde vaiga". Las aguas son sustento de una profunda cosmovisión mapuche (SKEWES; SILVA, 2007).

El tema de fondo del nguillatún del lago Neltume es el sacrificio ritual de un toro, el que es inmerso en el lago al concluir la ceremonia. El simbolismo que se despliega en la ceremonia renueva la simbiosis paisajística que se da entre humanos y no humanos. La ceremonia se celebra en un área ubicada en la cota 196, o sea, a nivel del lago, área que se inunda entre los meses de mayo y octubre.

El nigallatwé se organiza en virtud de la voluntad de uno de los miembros de la comunidad que quiere ofrendar el toro sacrificial. "Se dice: 'Yo voy a colocar esto'. Primero se cuentan los sueños ... La gente cuando está enferma recién acude aquí, antes no. Y antes no era así, la gente soñaba que tenía que hacer o quería dar gracias porque le iba bien, tenía animales, sembraba, no era necesario que se enferme para que venga. Ahora no, tiene que venir un machi decir ud. está castigado porque no está cumpliendo, tiene animales y no está dando las gracias, es por eso que usted está enferma. Ahí recién se empiezan a mover".

La ceremonia se prepara entre las autoridades a los pies del roble o pellin (nothofagus obliqua) que sirve a este fin. Se "hace una reunión antes de empezar, casi siempre se hacen en octubre, se avisa casa por casa. Está el ñempin, el sargento, el trutruquero, capitan, kalfumalén. El ñempin y la kalfumalen se quedan en su casa, y los otros salen a invitar y avisar. Por allá arriba en otro sector hay un pellín, también es sagrado, se lleva mudai y se conversa ahí". Antes de proceder a la ceremonia, las autoridades tradicionales (ngenpin, sargento y capitán) acuden al lago a fin de pedir permiso a Chumpal para llevar a cabo el rito. "Venimos a saludar el lago, le venimos a decir que mañana vamos a estar aquí, que nos espere. Y nos ganamos todos aquí, una vez sacrificados los animales. En el cementerio invitamos a los bisabuelos, a los espíritus que están ahí. Les avisamos que ellos vengan para acá al lago y acá venimos a decir que nos espere. Así que nos ganamos todos a la orilla y tenemos que estar pendientes de todo, no estar mirando para el otro lado, porque no todos tienen la posibilidad de ver, tiene que pasar un salmón, muy cerca tuyo. Pasa en el momento en que estamos acá, avisando que vamos a venir. Pasa siempre, pero no todos tienen la posibilidad de verlo, puede estar ahí mismo pero no lo ven. Hay que tirar el mudai al lago y empieza a correr por el lago y aparece el salmón, pasa de aquí para allá por la orilla. A veces salta. La idea es que siempre tiene que llegar al mudai, siempre. Nos ganamos todos en una fila y esperamos que aparezca el salmón. Uno no puede decir, mira ahí va, eso no se dice. Cuando se ve, nos retiramos y al otro día venimos al lago. Al otro día está calmo el lago." La figura sagrada de las aguas se hace presente en el rito de permiso a través de la figura de un pez que destaca por su vistosidad, atraído por la ofrenda de mudai. Ni un guillatún se ha hecho jamás sin que ello ocurra, según recuerdan los lugareños. No en vano, el lugar escogido coincide con las zonas de movimiento de los peces que habitan el lago (ver Mapa 2).

A las siete de la tarde del día escogido se empieza. Todos los miembros de la comunidad pueden asistir y si lo hacen deben llevar alimento. También pueden ofrendar animales para el sacrificio, principalmente corderos. "A esos animales se les saca el corazón vivo, tienen un sacrificio. La

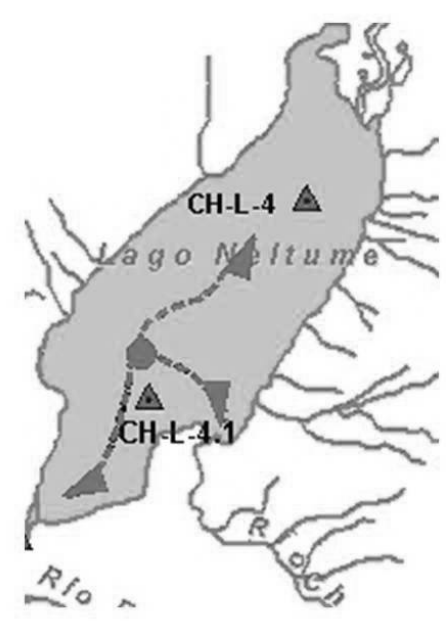

MAPA 2 - DESPLAZAMIENTO DE LOS PECES EN EL LAGO NELTUME (TOMADO DE INGENDESA 2010) 
persona que le saca tiene que tener sabiduría. Eso se hace alrededor de toda la gente, todos gritando y bailando, tiene que haber ánimo, tiene que hacerse en la mañana, no más de las 9, no puede pasar más del medio día, por eso se entra temprano. Primero se presenta como una ofrenda a dios. El ñempin (máxima autoridad de la ceremonia) tiene que orar por las personas, él es un intermediario, el conversa con dios, el invisible, el pide que a uno le vaya bien, que nos dé salud, suerte, que no llueva, uno pide nomás. Se pide un buen año", describe uno de los participantes de la ceremonia y prosigue:

Después de todo eso, ya se sacrifica el animal, y en ese caso son varias personas las que hacen ese trabajo porque cada uno tiene que sacarle a un animal. Una persona con un animal y otros sujetan las patas para que no se mueva, se coloca de espalda, siempre mirando hacia la cordillera, por donde nace el sol.

Durante el rito, tras el sacrificio del animal, su cuero relleno de piedras es arrastrado en carreta desde el palenque que sirve de rehue en la pampa hacia las aguas, acompañado en pares de los otros animales sacrificados. La ceremonia concluye con la inmersión en el lago del animal sacrificial. Don E. apunta:

Se tira el animal en tres botes, dos para los corderos, y uno para el toro, porque son dos pares, el animal tiene que ir acompañado con un cordero. Siempre tienen que ir acompañados con un macho y una hembra [...] Nosotros con tres botes tiramos el animal para adentro, el animal también tiene su... le echan piedras, y todo tipo de semillas [...] Y a ese animal se le echan clases de semillas de dos: dos papas, dos maíces, dos porotos, de todo. En mata, no en grano.

El toro representa al volcán y, por lo mismo, debe procurarse un animal cuyo color y vitalidad evoquen al macizo andino donde reside el pillán o espíritu mayor. "Es exclusivo del color del volcán, no es blanco, es neblino, con pintas negras. Es difícil conseguirlo porque no puede ser demasiado negro, ni muy blanco". El animal se ata al palenque en el campo ceremonial, el palenque "ni se mueve de ahí. Se inunda, pasan los años y ni se mueve de ahí, pretenden moverlo pero la naturaleza se encarga de dejarlo donde mismo". La participación de los hombres en el ritual es condición necesaria para su plena aceptación en la comunidad. En su vida, un adulto puede llegar a ofrendar hasta dos o tres toros y la preparación para cada uno de los sacrificios toma a lo menos dos años durante los que, no obstando sacrificios personales, se consiguen los medios para asegurar la ceremonia y el sacrificio ritual. Tras el nguillatún, quien ofrenda gana respeto y consideración entre sus semejantes, expresando ello en el ser su autoridad considerada por los demás.

El lago sedimenta las fuerzas espirituales a las que se debe la comunidad, la cual también cae bajo la custodia del ngen tutelar. "Las aguas tiene también su don, las aguas tiene su nombre, las montaña tienen su nombre también [...] Está el reino de la tierra, del cielo, del agua y de la montaña", señala don E. Bajo las aguas se conservan los animales sacrificados y espíritus que bajo la forma de cueros dan vida a un espacio numinoso y temido: pocos - si es que los hay - son las o los comuneros que se sumergirían en esas aguas. "Este año", se cuenta, "se mostró que esa parte donde se hunden los animales había una gran brillo metálico, como una antena. Se los mostramos a la sra Ángela. Y ahí de repente se desapareció, se fue otra vez". El agua es objeto de reverencia, especialmente en tiempo del nguillatún. "Nadie coloca sus manos en el agua, para ese día es sagrado. Hay otros días para ir a bañarse, pero ese día uno no se puede ni lavar la cara. Hay algunos que duermen y otros que amanecen, la idea es amanecer despierto. Los niños tampoco pueden tocar el agua, anda un cona, de esos que le llaman. A mí me toca salir, para que los niños no vayan a tocar el agua, porque o sino se empieza a nublar y el lago empieza con viento, se empiezan a formar olas. Pero si uno no hace nada, el lago permanece tal cual, tranquilito", dice uno de los participantes de la ceremonia. Al lago se tranquiliza con mudai.

La sacralidad del agua queda de manifiesto para el wetripantu, la celebración del renuevo del año para el solsticio de invierno. "Antes, en mes de junio, salíamos a las 5 de la mañana todos al agua, cuando niños, el agua esta bendecida por la mañana. Se hacía para la buena salud, al niño chico se le buscaba agua corriente para que tomara. Para que tenga salud, buena mente [...] El agua canta también, hace su alabanza a Dios, porque en el día está lo más tranquila, pero por la mañana canta. Por eso todos los esteros tiene su dueño, también alaban a Dios. Y por eso dicen que el agua es vivo, no es muertos", afirma una vecina. "Vive el agua porque corre", dice don R. Su ngen es el ngenco.

El agua constituye el trasfondo que une al volcán con el lago y al mundo humano como el no humano y la vida 
cotidiana con lo trascendente. La imagen del mundo está marcada por las venas del volcán, por las que circulan las aguas y las diversas familias, siguiendo una de las tradiciones más antiguas del pueblo mapuche, se allegan a los cursos de agua comprendidos entre el estero Huechulafquén y el rio Chan-Chan. Los humanos nacen de la tierra y se ordenan según las aguas: su incorporación al paisaje está en cierto modo preanunciada. El parentesco se inscribe en el paisaje. Las casas se ordenan tomando como referencias las quebradas que se asocian con las distintas líneas familiares, dejando a la vista el volcán y el lago.

El mestizaje no alteró el carácter mapuche del territorio y fueron las mujeres quienes más empeño pusieron en conservar su identidad, involucrando a sus hijos y parientes en las organizaciones tradicionales del pueblo. "Ahí le dijimos a Don José Catriman que nos juntemos en el cementerio con los antiguos, que solían hacer guillatwé para que dé fuerza a sus hijos. Luego paró de nevar, pero llovía, después hacía calor, como ahora; y nosotros bailamos. Después, por la noche, dos pulgadas de nieve, después llovía, y de tener un metro cincuenta pasó a nada. Por eso nosotros tenemos fe. Por eso nosotros tenemos fe. Porque él nos protege, porque hacemos nguillatún". Así pudieron sobrevivir el nguillatún, el longko (la autoridad tradicional), los capitantes, los werkenes (mensajeros), la calfumalen (o joven pre-puber que representa el cielo y es insignia de la autoridad ancestral) sin quien no se puede realizar el guillatún) y demás figuras de autoridad en el medio comunitario.

Los seres humanos son del paisaje y, al morir, se transforman en paisaje. Sus espíritus siguen presente y para las juntas se les invoca. La transformación de los seres humanos en paisaje se sella con la erección de descansos a través de los que se demarcan la separación entre lo humano y lo sobrenatural. Los descansos son lugares recordatorios de los difuntos. Tal como en Calafquén, "el espacio cotidiano de la vida y el espacio numinoso de la muerte se espacian en el camino que recorre el difunto en su viaje hacia el territorio del cementerio. Antes de abandonar la casa, se marca la partida definitiva por un 'descanso' [...] Este fue el bastidor existencial, 'centro de lo contemplado', que sustentó el habitar de las bandas Pitrén en los comienzos de nuestra era" (ALVARADO; MERA, op. cit.).

Los descansos en el mundo mapuche-huilliche corresponden a pequeños altares erguidos en la memoria de las y los difuntos. La presencia de este simbolismo religioso denota, por una parte, una forma de articular los espacios cotidianos y sagrados, y, por la otra, de separar lo comunitario de lo familiar. La existencia de esta práctica

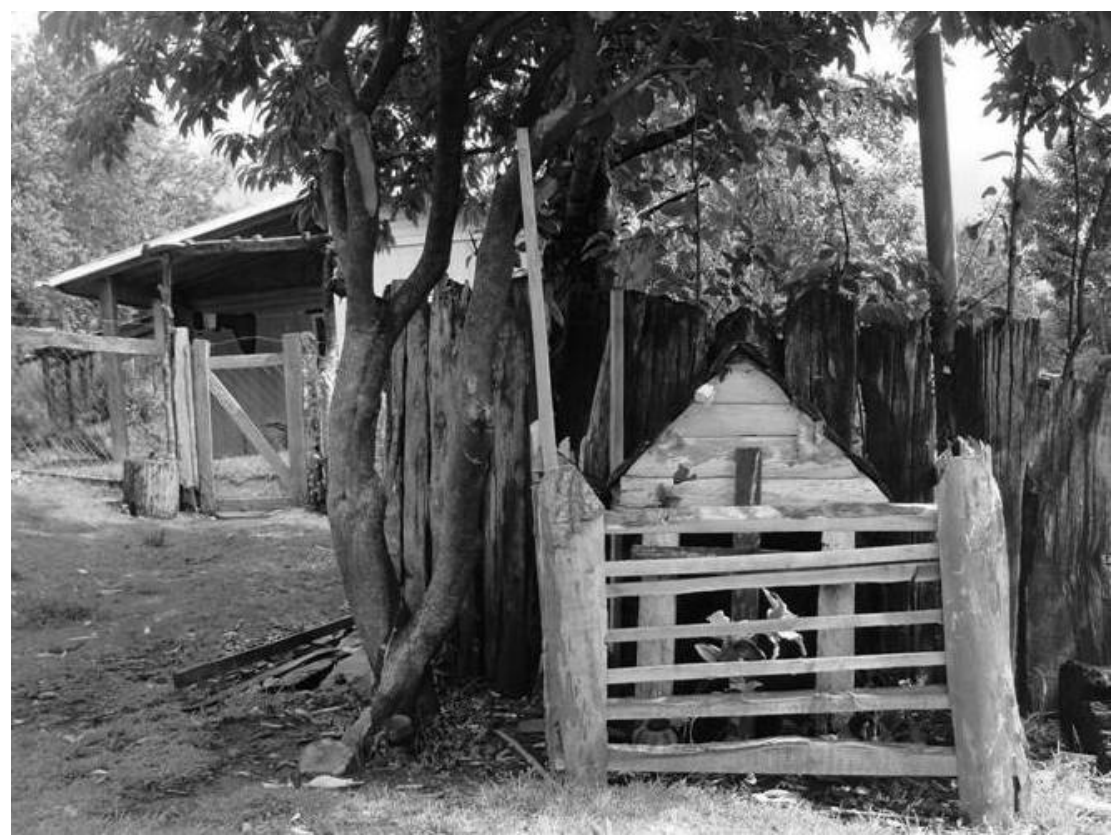

FOTO 2 - UN DESCANSO EN EL LAGO NELTUME (2010) 
ritual mortuoria ha sido poco documentada en la literatura, aún cuando es una parte integral del paisaje habitado por las familias mapuche-huilliche de las zonas cordilleranas.

La arquitectura de los descansos adopta la forma de un casa o alero de menos de un metro de altura ornamentado con una cruz y dispuesto a los pies de un árbol, de preferencia un pellín (Nothofagus obliqua). El descanso se ubica dentro del predio a un centenar de metros de la vivienda ocupada por la familia del difunto o difunta. El sitio señalado para el descanso es elegido por la familia o está estipulado con anterioridad por la misma persona. Algo común a la mayoría de los descansos es que a la hora de elegir el sitio, este siempre se sitúa bajo la sombra de un árbol y en el límite de la propiedad. En la mayoría de los casos, lo único que se constituye como descanso es el árbol.

El descanso se construye en relación al espíritu de la persona, el que puede volver al mundo de los vivos. En la cultura mapuche, el espíritu se distingue del alma y la persona está constituida por diversos componentes espiri-

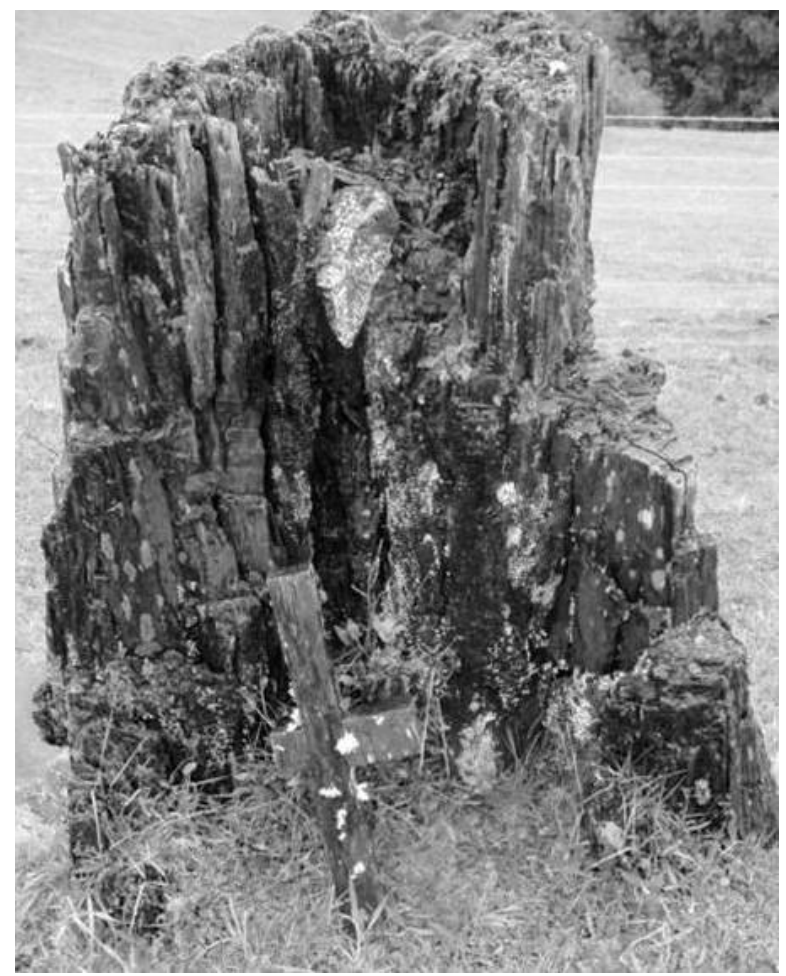

FOTO 3 - LA METAMORFOSIS DE UN DESCANSO (LA CRUZ, ABAJO, ES REEMPLAZADA POR EL ÁRBOL) tuales, siendo el espíritu que puede merodear en las casas gimiendo, haciendo sonar las cosas o provocando fuegos dentro de la ruka.

La construcción que se hace en memoria del difunto termina por derruirse y finalmente sólo queda el árbol en memoria del difunto y, en tanto tal, es usado por la comunidad como una señal para describir el territorio. Los árboles, en este sentido, fijan la geografía social del paisaje, de modo que cada lugareño o lugareña era capaz de identificar las diversas posiciones en el territorio obre la base de estos referentes arbóreos: en otro tiempo es probable que hubiésemos preguntado, a la Evans Pritchard, dime de qué árbol estamos hablando para saber de quién se trata.

En el mapa que sigue se muestran la distribución de descansos en la comunidad Juan Quintuman. El patrón es claro toda vez que los descansos se concentran en las proximidades de los cursos de agua, siendo protegidos por la montaña en la parte nororiental y por el cementerio, el árbol ritual y el sitio sagrado del nguillatún en la parte suroccidental. Fuera de estos márgenes, hay algunas animitas junto a las rutas camineras que caracterizan el fervor popular chileno.

\section{El paisaje de la memoria}

El enraizamiento de la comunidad es fácilmente soslayado en la visión que se construye a partir del EIA. Esta visión hace caso omiso de la existencia de un patrón de poblamiento territorial y opta por entenderse con un grupo entendido como familias empobrecidas que se caracterizan por ser portadoras de una cierta tradición cultural. La llegada de ENDESA y de sus expertos representa una intersección donde la historia del capitalismo avanzado horada el subsuelo cordillerano encontrándose de lleno con la faz - sólo con la faz - de una población que habitaba de otro modo el mundo. El habitus del consultor, intermediario fugaz de las historias laterales, lleva a traducir de modo unidimensional la complejidad que se mueve al otro lado del espejo. En su inventario, el EIA sólo se ve a sí mismo reflejado en la exterioridad de las materialidades ajenas. La empresa puede proceder reorganizando un mundo que, en definitiva, le es desconocido.

Todas las decisiones que se desprenden del EIA son equívocas. La represa está llamada, en este sentido, a desarreglar los arreglos del paisaje. Y con ello, a las gentes salidas de la tierra. La vida humana, hecha de sus propios 


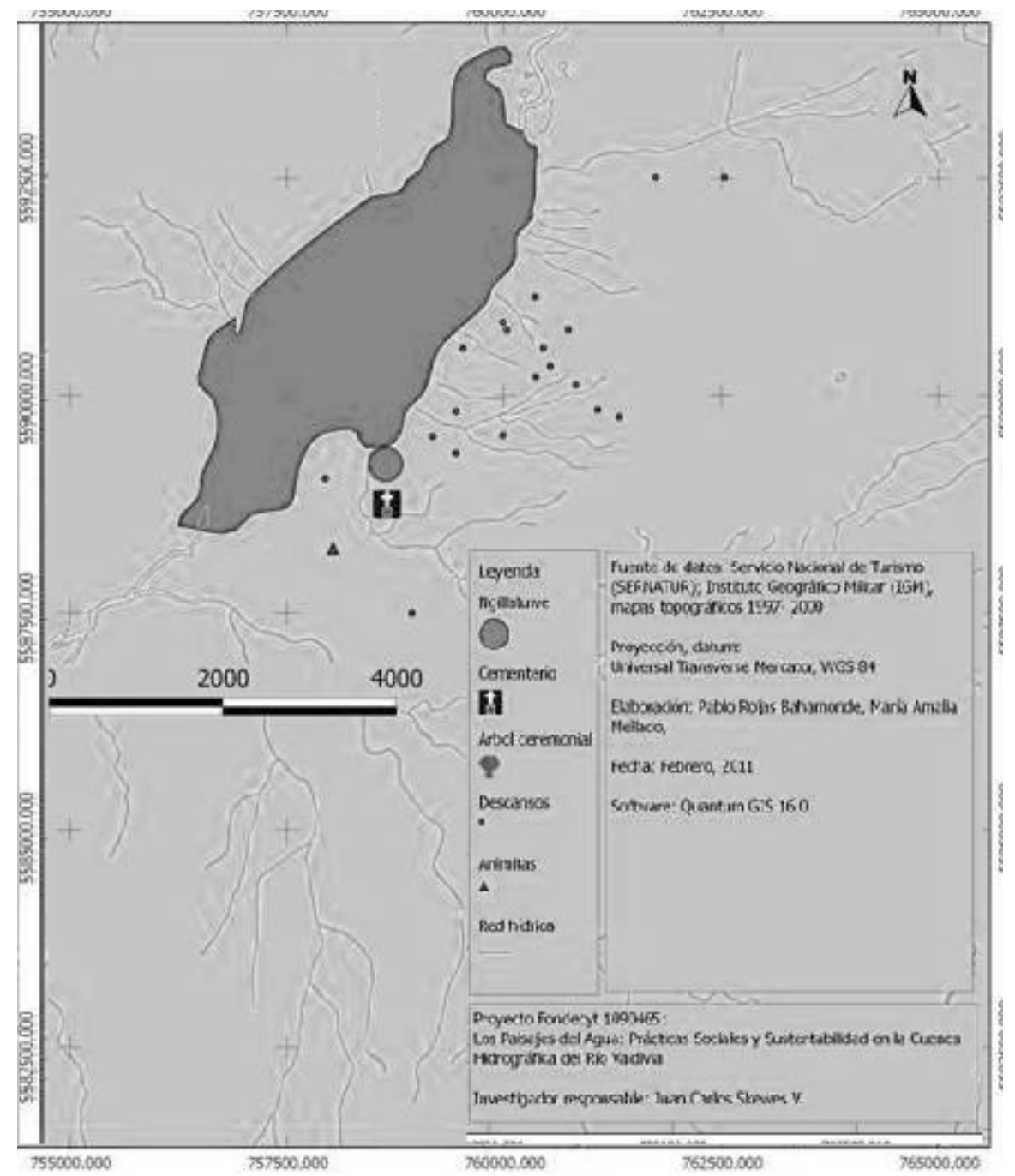

MAPA 3 - DISTRIBUCIÓN DE LOS DESCANSOS EN LA COMUNIDAD JUAN QUINTUMÁN

resuellos, se va a percudir, se va a "maltratar o ajar la tez o el lustre o viveza de las cosas, o por el demasiado uso de ellas" (REALACADEMIA ESPAÑOLA DE LA LENGUA 1737, p. 213). "Y si se hace [la represa] ¡cuánto nos va a percudir! ¡Cuánto árbol se va a secar! Árboles frutales se van a secar, cuánto mal por el agua, por nuestras plantas medicinales. Por eso nosotros estamos luchando, por nuestra tierra", reclama una comunera.

El patrón paisajístico se altera sustantivamente con la instalación de la Central Hidroeléctrica Neltume que incluye la construcción de una bocatoma para captar las aguas del río Fuy, "para luego ser conducidas hasta la caverna de máquinas, mediante una obra de aducción subterránea de aproximadamente 10 kilómetros de longitud, aprovechando la diferencia de cota entre ambos extremos. Las aguas luego de generar, se entregarán al lago Neltume ... La caverna de máquinas, se localizará de forma subterránea bajo el territorio de la comunidad Juan Quintumán, a unos $850 \mathrm{~m}$ del borde oriental del lago Neltume" (INGENDESA, 2010, Anexo W, p. 2). Se trata de un proyecto de 755 millones de 


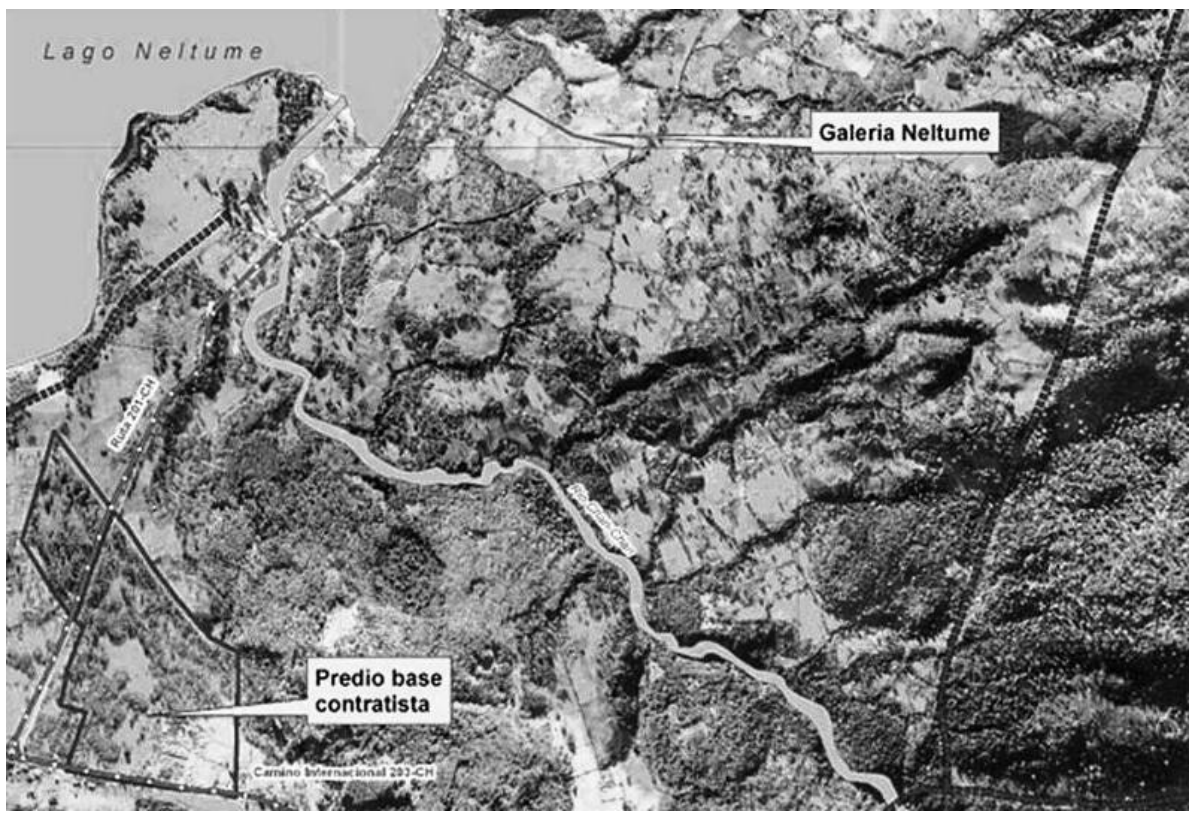

MAPA 4 - EL TRAZADO DEL PROYECTO (TOMADO DE INGENDESA, 2010)

dólares americanos y con una vida útil estimada de 50 años (DIARIO EN ACCIÓN.CL, 2010).

Una vez concluida la construcción de la Central, la comunidad verá desaparecer el campo ceremonial, sus tierras serán horadadas para la construcción de la caverna de máquinas y el núcleo poblacional será atravesado y divido en dos por un ducto. Tal intervención es sintomática de una descomposición radical del territorio que se asocia con el quiebre social. Mediante subsidios y promesas de empleo la empresa lograr atraer la fuerza de trabajo juvenil y satisfacer necesidades básicas de residentes enfrentados a la precariedad económica. Con el apoyo así obtenido, ENDESA organiza a la comunidad que le es leal en torno del agua. Lo hace de modo subrepticio, dejándose infiltrar por algunas ideas nativas y reintroduciéndolas bajo la forma de respuestas dadas a las necesidades insatisfechas. En la reunión celebrada el 9 de agosto de 2010 en la sede, a la que ahora no tiene acceso parte importante de las y los comuneros, recuerdan a la Asamblea: "El agua es vida". Por eso es que han apoyado la gestión de un Comité de Agua Potable Rural. "Recuerden que tienen necesidades, pero ustedes tienen que evitar que se opongan a este proyecto". La oposición, claro está, es inevitable y no sólo por el antagonismo frente al proyecto sino por ver que lo que
Chao Dios les ha concedido ahora deberá ser pagado. Paradojalmente el empalme para la conexión del agua potable rural pretende hacerse en el lugar donde las familias más necesitadas prohíben a la empresa su entrada.

"Endesa quiere destruir nuestro campo ceremonial, para ellos nuestro palenque y nuestro newen son cualquier cosa, nuestro palenque y newen tiene mucho poder para nosotros, tenemos fe en Chao Dios, por eso queremos a nuestro nguillatue, por eso pedimos a las autoridades ayuda, porque nosotros queremos vivir tranquilos y en paz". "Si se pierde el palenque, ¿a dónde vamos a ir? ¿A dónde vamos a ir a nosotros, dónde nos vamos a poner? Nos quieren dejar del otro lado allí, ponernos casa [...] Nuestros abuelos me dijeron que venían los extranjeros a enterrarnos en el barro. Y eso no más, ahora si quieren hablen".

El territorio, bajo las nuevas condiciones, se presenta paradojalmente reflejado en estructuras duras del nuevo proyecto. Los cursos de agua son sustituidos por tuberías para conexiones domiciliarias, el domicilio de los seres espirituales es reemplazado por la caverna de máquinas, el sitio ceremonial se sumerge bajo las aguas, y la ruta ritual que acompaña a los difuntos en su último peregrinar es evocada por un ducto de acero. El mundo, bajo estas condiciones, se ha vuelto ajeno y con ello los espíritus 


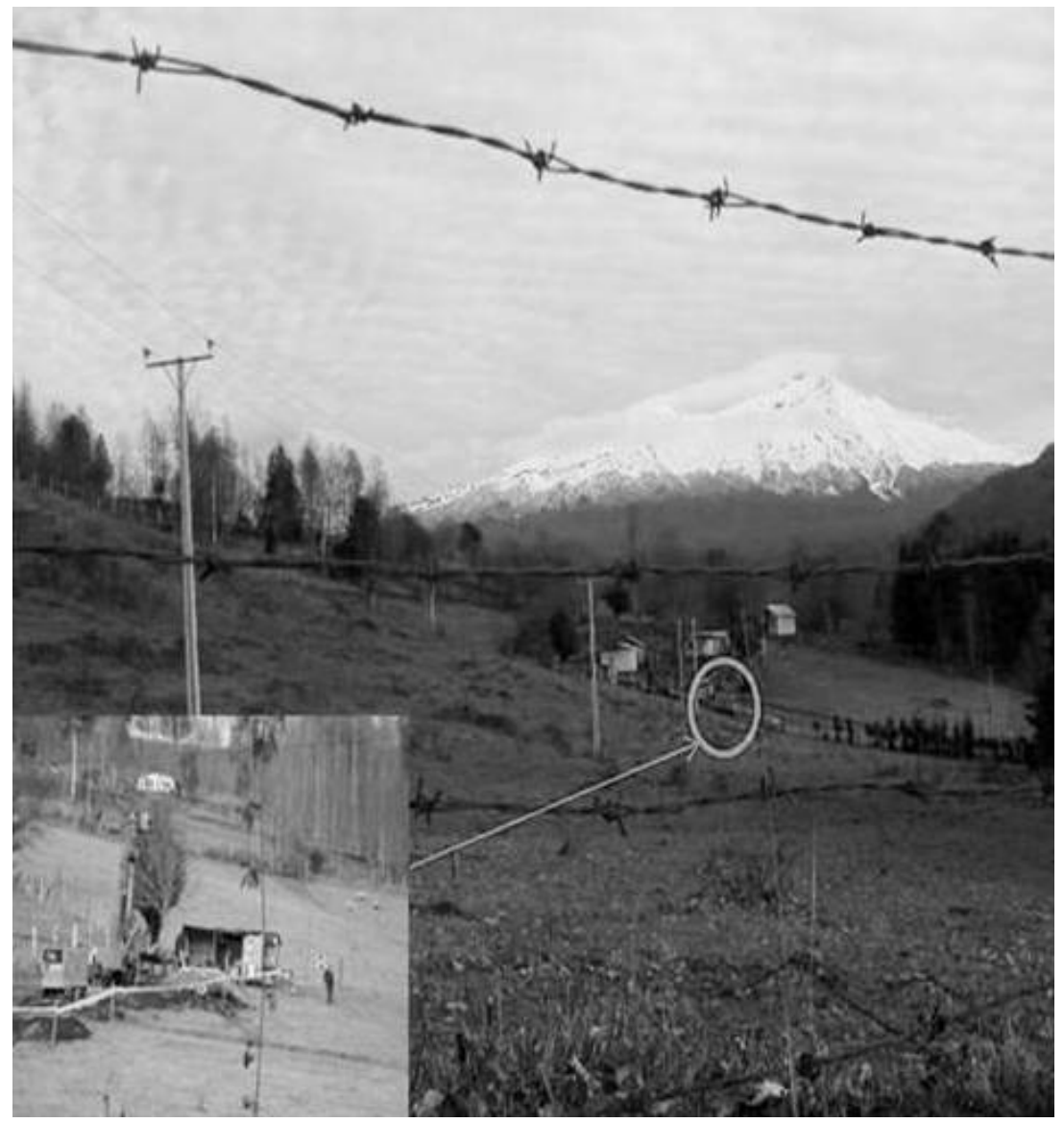

FOTO 4 - QUIEBRE PAISAJÍSTICO PRODUCIDO POR ENDESA.

protectores abandonan sus pagos: "Cuando se interviene un lugar se quedan los gnen sin lugar. Se van. Ellos son dueños de aquí", dice doña María P. Sólo queda el testimonio de los vivientes convertidos en árboles.

\section{Conclusiones}

Los paisajes contienen la memoria del colectivo. La comunidad se reconoce a través de sus relaciones recíprocas mediadas por el paisaje y el paisaje mismo asegura su continuidad a través de los seres humanos que son parte suya. Estas relaciones están inscritas tanto en los dominios inmateriales - el mito, la cosmovisión, el recuerdo - como materiales - el campo sagrado, el descanso, el cementerio, los volcanes - y se disponen de acuerdo a un patrón socioespacial. Este patrón se reproduce a través de las prácticas cotidianas y de las prácticas rituales. Se nace de la tierra y, al morir, el ser humano se transforma en la tierra. Los árboles, junto a los que se han erguido los descansos representan la transformación del humano en no humano y en hitos de un sistema que se sostiene a través de los tiempos.

El tránsito de la memoria de los paisajes a los paisajes de la memoria marca la reestructuración de una localidad por la vía de la intervención externa. Esta intervención reclama una mirada que permite cercenar lo que de otra manera la tornaría imposible. El EIA cumple esa función. Lo hace mediante la aplicación formulaica de un procedimiento analítico, catastral y cosificador que, en buena parte, encarna la cosmología occidental nativa. 
¿Es posible pensar un EIA de otro modo? La respuesta depende de las prioridades según sea el énfasis eficientista o sustantivista que se le quiera dar. Desde el último punto de vista, esto es, según el cual es la dimensión socioambiental la que se tiene por sustentable, un EIA no podría sino partir de la pregunta acerca del arraigo que históricamente ha dado lugar a un determinado patrón paisajístico. La comunidad no es algo que posea o no ciertas cosas, la comunidad es el arreglo a que históricamente se ha accedido en un territorio entre humanos y no humanos. ¿Quiere decir que la articulación con los procesos que se desencadenan desde

\section{Bibliografía}

ADAN, L.; MERA, R.; BAHAMONDES, F. Historia cultural de la cuenca del río Valdivia: Proposiciones a partir del estudio de sitios alfareros prehispánicos e históricos. Revista Austral de Ciencias Sociales, v. 12, p. 5-30, 2007.

ALARCÓN, M. Panguipulli: El pueblo y la comuna. Tesis (Profesor Primario) - Universidad Católica de Chile, 1958.

ALDUNATE, C. En el país de los lagos, bosques y volcanes. In:__ Chile antes de Chile. Santiago: Museo Chileno de Arte Precolombino, 1997.

ALVARADO, M.; MERA, R. Estética del paisaje y reconstrucción arqueológica. El Caso de la región del Calafquén (IX y X Región-Chile). Chungará, Revista de Antropología Chilena, v. esp., p. 559-568, 2004.

BEDOYA, E.; MARTÍNEZ, S. De la economía política: balance global del ecomarxismo y la crítica al desarrollo. En VIOLA, A. (Ed.). Antropología del desarrollo. Teoría y estudios etnográficos en América Latina. Barcelona: Paidós, 2000.

COMISIÓN VERDAD HISTÓRICA Y NUEVO TRATO. Informe de la Comisión Verdad Histórica y Nuevo Trato con los Pueblos Indigenas. Santiago de Chile: Comisionado Presidencial para Asuntos Indígenas, 2008.

CRUMLEY, C. L. Historical ecology: A multidimensional ecological orientation. En CRUMLEY, C. L. (Ed.). Historical ecology. Cultural knowledge and changing landscapes. Santa Fe, New Mexico: School of American Research Press, 1994.

DESCOLA, P. La selva culta. Simbolismo y praxis en la ecología de los Achuar. Quito: Abya-Yala, 1996.

DIARIO EN ACCIÓN. Endesa ingresa a Corema Estudio de Impacto Ambiental de proyecto Neltume y ambientalistas el exterior es inviable? ¿que lo que ha de prevalecer es lo que siempre ha existido? Indudablemente que no. Un EIA podría contribuir a anticipar la forma como los diseños paisajísticos en un determinado territorio pueden metabolizar los cambios que inevitablemente habrán de ocurrir. Lo que cambia es el modo de hacer las preguntas: ¿cómo es posible - si ello es necesario - generar electricidad desde aquí? ¿Cómo habrían de generar energía los volcanes, ríos, lagos y seres humanos del lago Neltume? Tales no son preguntas técnicas. Son interrogantes socioambientales.

la acusan de "mediocre". Disponible en: <http://www.diarioenaccion.cl/index.php?option $=$ com_content\&view $=$ articl e\&id=370557:ambietalistas-cuestionan-ingreso-del-eia-del-proyecto-neltume-a-corema-endesa-es-un-empresa-mediocre- aseguran\&catid $=109$ : estadisticas\&Itemid $=488>$. Acceso en: febrero de 2011.

ENDESA CHILE 2009. Informe de Medio Ambiente. Disponible en: $<$ http://www.endesa.cl/Endesa_Chile/gobierno_corporativo/Informe_de_Medio_Ambiente_2009.pdf $>$. Acceso en: abril de 2011.

FOERSTER, R. Introducción a la religiosidad mapuche. Santiago: Universitaria, 1995.

GIDDENS, A. The constitution of society. Outline of the theory of structuration. Cambridge: Polity Press, 1984.

HARVEY, D. Capitalismo: la fábrica de la fragmentación. En: . Espacios del Capital. Madrid: Akal, 2007.

El "nuevo" imperialismo. Sobre reajustes espacio temporales y acumulación mediante desposesión. Revista Herramienta, v. 27, 2004. Disponible en: $<\mathrm{http}: / /$ www.herramienta. com.ar/modules.php?op=modload\&name $=$ News\&file $=$ article $\&$ sid $=286>$. Acceso en: enero de 2008.

INGENDESA. Estudio de Impacto Ambiental Proyecto Central Hidroeléctrica Neltume. 06334-05-05-SGMA-EIA-001. Santiago, ENDESA, 2010.

INTERNATIONAL ASSOCIATION FOR IMPACT ASSESSMENT (IAIA). Principles of Environmental Impact Assessment Best Practice. In collaboration with Institute of Environmental Assessment, UK, 1999. Disponible en: <http://www.iaia.org/ publicdocuments/document-search.aspx $>$. Acceso en: febrero de 2011. 
JALABERT, Daniela. Transformaciones del paisaje en la zona cordillerana de la región de Los Ríos desde la década del cincuenta hasta la actualidad: Estudio de Caso en el Lago Panguipulli. Informe de Práctica Profesional (Título de Antropóloga) - Universidad Austral de Chile, 2010.

LEFF, E. On the social reappropriation of nature. Capitalism, nature, socialism, v. 10, n. 3, p. 89-104, 1999.

Globalización, racionalidad ambiental y desarrollo sustentable. 2003. Disponible en: <http://www.ambiente.gov. ar/infotecaea/descargas/leff08.pdf $>$. Acceso en: marzo de 2011.

LEMOS, Chélen Ficher. Audiências públicas, participação social e conflitos ambientais nos empreendimentos hidroelétricos: os casos de Tijuco Alto e Irapé. Rio de Janeiro: Instituto de Pesquisa e Planejamento Urbano (UFRJ), 1999.

MASSEY, D. For space. London: Sage, 2007.

MEMORIAL A LAS VICTIMAS DE LA DICTADURA. $E l$ complejo forestal y maderero de Panguipulli. Disponible en: $<$ http://www.memoriamir.cl/pagina/neltume.htm\#historial $>$. Acceso en: octubre de 2010.

MELUCCI, A. La acción colectiva como construcción social. Estudios Sociológicos, v. 9, n. 26, p. 357-364, 1991.

MUNITA, D., ADAN, L.; MERA, R. Prospecciones arqueológicas terrestres en áreas lacustres piemontana, cordillerana y pampeana del centro sur chileno. Magallania, v. 38, n. 1, p. 247-268, 2010.

NAVEH, Z. What is holistic landscape ecology? A conceptual introduction. Landscape and Urban Planning, v. 50, p. 7-26, 2000 .

O'CONNOR, J. Natural causes: essays in ecological Marxism. New York: Guilford, 1998.

ORTNER, S. Anthropological theory since the 1960s. Comparative Studies in Society and History, v. 26, n. 1, p. 126-166, 1984.

PATTERSON, T. C. Toward a Properly Historical Ecology. En: CRUMLEY, C. L. (Ed.). Historical Ecology: Cultural Knowledge and Changing Landscapes. Santa Fe, New Mexico: Society of American Research Press, 1994.

PAULSON, S., GEZON, L.; WATTS M. Locating the political in political ecology: An introduction. Human Organization, v. 62, n. 3, p. 205-217, 2003.

POLANYI, K. The Great Transformation. Boston: Beacon Hill, 1944.
REAL ACADEMIA ESPAÑOLA DE LA LENGUA. Diccionario de la lengua castellana, en que se explica el verdadero sentido de las voces, su naturaleza y calidad, con las phrases o modos de hablar, los proverbios o refranes, y otras cosas convenientes al uso de la lengua. Compuesto por la Real Academia Española. Tomo quinto. Que contiene las letras O.P.Q.R. Madrid. Imprenta de la Real Academia Española, por los herederos de Francisco del Hierro. 1737. Disponible en: $<$ http://buscon. rae.es/ntlle/SrvltGUIMenuNtlle? $\mathrm{cmd}=$ Lema\&sec $=1 \cdot 0.0 .0 .0>$. Acceso en: noviembre de 2010.

RICHARDSON, M. Place, Narrative, and the Writing Self: The Poetics of Being in the Garden of Eden. Southern Review, v. 35, n. 2, p 330-338, 1999.

RIQUELME, M. Neltume. Tesis (Profesor de Educación Básica) - Universidad Católica de Chile, 1968.

RIVAS, R. Desarrollo Forestal de Neltume: Estado y Trabajadores (1924-1990). Tesis de Grado (Profesor de Estado en Historia) - Universidad Austral de Chile, 2006.

SCOTT, J.C. Seeing like a State. New Haven: Yale University Press, 1998.

SELLIN, E. A congruence of landscape and the mind. Literary Review, v. 39, n. 4, p. 492-503, 1996.

SCHMINK, M.; WOOD, Ch. The political ecology of Amazonia. En: LITTLE, P. D.; HOROWITZ, M.M. (Eds.). Lands at risk in the Third World: Local level perspectives. Boulder, CO: Westview Press, 1987.

SILVERMAN, H. The Space and Place of Death. Archaeological Papers of the American Anthropological Association, v. 11, n. 1, p. 1-11, 2002.

SKEWES J. C.; SILVA, M. Elementos para una comprensión ecológico-cultural de las narraciones míticas acerca de las aguas y los seres del agua en la cosmovisión mapuche huilliche. En: RODRÍGUEZ, C.; BROWNE, R.; DEL VALLE, C.; FIGUEROA, S. (Eds.). Sociedad y cultura: reflexiones transdisciplinarias. Valdivia: UACh, UFRO, MECESUP, 2007.

STEPHENS, J. Karalee Rock: The Formation of Place and Identity. Urban Policy and Research, v. 20, n. 1, p. 87-99, 2002.

STOKOWSKI, P. A. Languages of place and discourses of power: Constructing new senses of place. Journal of Leisure Research, v. 34, n. 4, p. 368-383, 2002.

TOLEDO, V. Pueblo Mapuche. Derechos Colectivos y Territorio. Santiago: Chile Sustentable, 2007. 
VERGARA J. I.; MASCAREÑO A.; FOERSTER R. $L a$ propiedad huilliche en la provincia de Valdivia. Santiago de Chile: Corporación Nacional de Desarrollo Indígena, 1996.

WEERATUNGE, N.; AGRAWAL, A.; GURURANI, S.; MILTON, K. Nature, harmony, and the Kaliyugaya: Global/local discourses on the human-environment relationship/comments/ Reply. Current Anthropology, v. 41, n. 2, p. 249-269, 2000.
ZHOURI, Andréa. Justiça ambiental, diversidade cultural e accountability. Desafios para a governança ambiental. Revista Brasileira de Ciências Sociais, v. 23, n. 68, p. 97-107, 2008.

Recebido em fevereiro de 2011. Aceito em abril de 2011. Publicado em junho de 2011. 